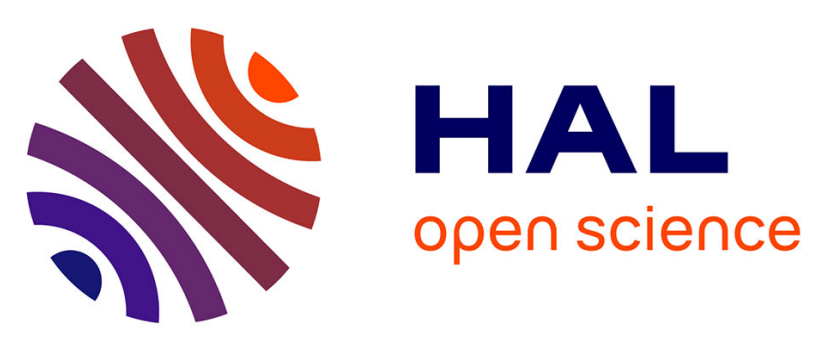

\title{
RFID tags for cryogenic applications: Experimental and numerical analysis of thermo-mechanical behaviour
}

\author{
Romain Cauchois, Man Su Yin, Aline Gouantes, Xavier Boddaert
}

\section{To cite this version:}

Romain Cauchois, Man Su Yin, Aline Gouantes, Xavier Boddaert. RFID tags for cryogenic applications: Experimental and numerical analysis of thermo-mechanical behaviour. Microelectronics Reliability, 2013, 53 (6), pp.885-891. 10.1016/j.microrel.2013.02.009 . emse-00859796

\section{HAL Id: emse-00859796 \\ https://hal-emse.ccsd.cnrs.fr/emse-00859796}

Submitted on 9 Sep 2013

HAL is a multi-disciplinary open access archive for the deposit and dissemination of scientific research documents, whether they are published or not. The documents may come from teaching and research institutions in France or abroad, or from public or private research centers.
L'archive ouverte pluridisciplinaire HAL, est destinée au dépôt et à la diffusion de documents scientifiques de niveau recherche, publiés ou non, émanant des établissements d'enseignement et de recherche français ou étrangers, des laboratoires publics ou privés. 


\title{
RFID tags for cryogenic applications: experimental and numerical analysis of thermo-mechanical behaviour
}

\author{
Romain Cauchois ${ }^{*} \dagger$, Man Su Yin, Aline Gouantes, Xavier Boddaert \\ Centre Microélectronique de Provence, École Nationale Supérieure des Mines de St-Etienne, 880 avenue de Mimet 13541 Gardanne, France \\ * Corresponding author: Tel.: +31 404020 637; fax: +31 404020 699. E-mail address: romain.cauchois@tno.nl \\ ${ }^{\dagger}$ Now at: Holst Centre / TNO High Tech Campus 31, PO BOX 8550, 5605 KN Eindhoven, The Netherlands
}

\begin{abstract}
:
RFID solutions will improve the traceability of biological samples stored at low temperature (77K) in biobanks. To achieve this goal, the reliability of RFID tags is essential. In this paper, we focus on the reliability aspect of RFID tags in harsh environment and more specifically to assembly design optimization through numerical simulations and accelerated life tests. A packagedimensioned model and a wire-interconnect centered model have been used to assess stress distribution in the package and wire bonds. We also develop a specific versatile test bench to apply thermal cycling while monitoring the functionality of the tags. We investigate 3 different tag configurations and demonstrate that the main failure mode is related to wire breaks. The occurrence of this failure depends mainly on the nature and thickness of the encapsulant resin which induce compressive and tensile stresses during thermal cycling. FEM results are in good agreement with observed failures.
\end{abstract}

\section{Introduction}

Improving safety, quality and value of health care is the main concern of hospital staff. This goal can only be reached if disease is well diagnosed and if appropriate treatment is developed and safely delivered. Biorepositories, or biobanks, have thus been created to support scientific investigations of pathologists and medical researchers. Biorepositories are centres where biological samples are collected, processed and eventually stored at extremely low temperature until a sample request is formulated by a scientist. To ensure continuity of care records, radio frequency identification (RFID) solutions are investigated to ensure traceability of these samples without any loss of biological integrity [1-3]. Where barcode processing turns out to be slow and error-prone, RFID solutions are very fast and don't need any line of sight for treatment.

RFID components offer huge assets in traceability issues given the amount of stored data and the ease to update them on the fly. Since RFID tags can be packaged directly within the cryotube or pocket frames of repositories, sample history is stored and permanently enclosed with the sample without any risk of mishandling or file loss. Thousands of biological samples are commonly stored in cryogenic tanks that are filled with liquid nitrogen to prevent any deterioration of tissues. Inherently to the biorepository system, many samples can then be stepped out of storage tanks to room temperature for few seconds when one of them has been requested for medical examination or analysis. Nonetheless, such tags were not hitherto developed specifically for cryogenic environments where temperature can reach $-160^{\circ} \mathrm{C}$. More, impact of temperature variation on the tag integrity has not yet been studied for medical implementations.

This paper focuses on the reliability aspect of smart tag technologies in harsh environment, and more specifically to assembly design optimization through numerical simulations and physical characterization. Three different designs and material configurations are tested to shed light on assembly weaknesses and to give trends in order to specifically design micropackages for cryogenics.

Numerical simulations through finite element modelling (FEM) are a fast, efficient and low-cost method for evaluating the stress distribution inside RFID components during a thermal load. FEM simulations have been popularly used to analyze reliability effects of various design parameters and to validate best suited design scenarios for new products [4-7]. A package-dimensioned model and a wired-interconnect-centered model previously developed will be used in this paper to assess stress distribution with a limited computation time and an acceptable error range $[8,9]$.

Complementary to FEM, accelerated life tests (ALT) are performed to worsen emergence of failure modes which would have appeared anyhow after a high number of cycles. These tests are carried out by cycling electronic components with a greater thermal difference than what they will face in operation. Thus, failure analysis is of utmost importance to attest that observed defects are representative of the real behaviour and not only artefacts generated by the accelerated life test.

\section{Experimental protocol}

\subsection{Apparatus}

The few commercial types of equipment achieving thermal shock tests are very limited in terms of accessible temperatures. Some laboratories have nonetheless built automatic systems to perform customized thermal shock tests between air and liquid nitrogen, in a vertical movement [10]. Some of them have also implemented a fan to disperse the cold gas that locally surrounds the silicon die, thus enhancing thermal exchange with ambient air [11]. Based on the specific needs of 
accelerated tests for components operating in extreme conditions, we developed a dedicated bench for applying thermo mechanical constraints coupled with RFID implementation for monitoring the functionality of components during experiments (Figure 1).

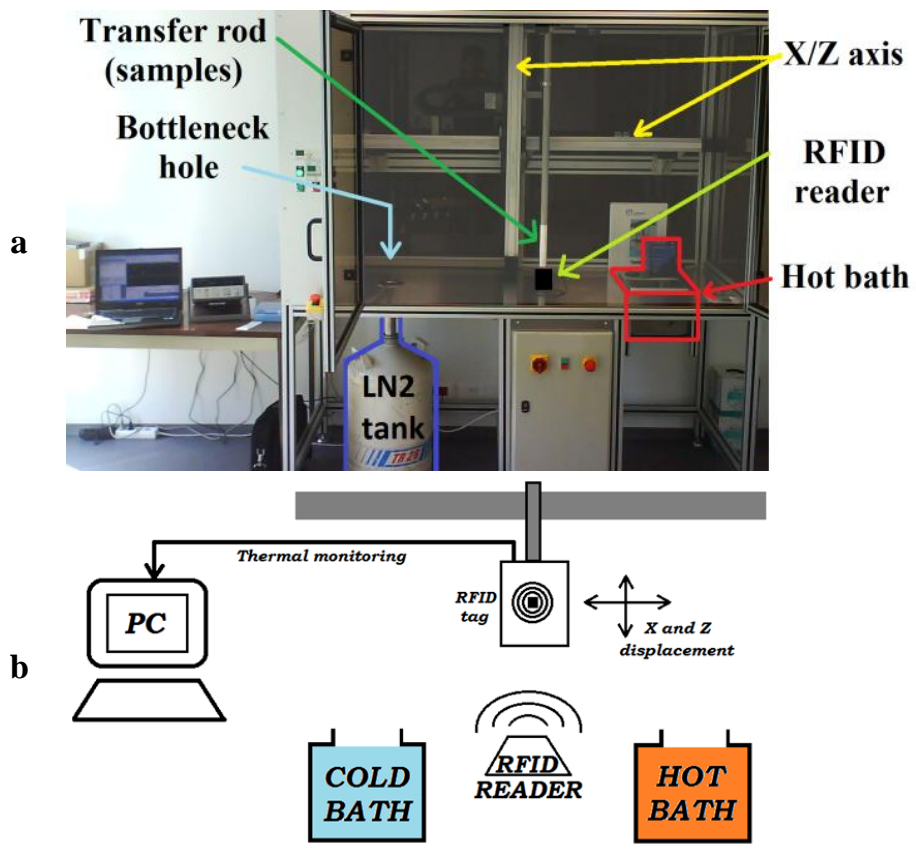

Figure 1: Accelerated life test apparatus (a) and schematic principle (b).

The equipment is similar to a lab bench where a motorized robot travels between three different positions thanks to a dual axis system (along $\mathrm{x}$ and $\mathrm{z}$ axis). This equipment, called $\mathrm{T}$ REX (for "Thermal Reliability EXperiment") has been designed to realize a high number of cycles with a transfer time of 13 seconds between hot and cold baths. The latter is filled with fluorinated heat transfer fluid, whereas the former is made of a liquid nitrogen bath at $-196^{\circ} \mathrm{C}$ in a Dewar. The third station is a loading/unloading position. T-REX can perform tests between liquid nitrogen and room temperature or between liquid nitrogen and a warm bath, up to $250^{\circ} \mathrm{C}$. A bottleneck has been placed above the Dewar to contain dry nitrogen which acts as a thermal buffer to limit heat exchange between the liquid and ambient air. Finally, the transfer rod can be adapted either with a bucket or with a sample holder at the end of the cane. A thermal monitoring sensor has also been implemented jointly with a RFID monitoring device (a contactless reader) performing functionality tests on the fly, without stopping the experiment. The integrated circuit identification (IC-ID) of the tag is thus read to discriminate in real time which tag is still in operation when reaching the reader position. Since the vicinity of the tag has to be totally free of any metallic part, the rod end and the bucket are made of polytetrafluoroethylene (PTFE) which allows the signal transmission without significant disruption. In addition to that, considering the number of tested tags, an anti-collision algorithm has been developed to discriminate signals from each tag in the vicinity of the transponder.

\subsection{Specimens description}

Three RFID tags commonly used in passports or for smartcards applications have been tested. According to the microelectronics standard, they are based on ISO/IEC 14443 communication protocol [12]. For confidentiality reasons, they are simply referred to as configurations 1, 2 and 3.They only differ by their geometry and materials employed, as detailed in Figure 2 and Table 1. Mechanical and thermal properties of involved materials are summarized in Table 2. Nonetheless, all three configurations possess identical bonding loop profile with the same gold wire and a neck height over the die $\left(\mathrm{H}_{\text {neck }}\right)$ of $130 \mu \mathrm{m}$. A similar process is indeed performed for those configurations with steps using identical set of temperature, ultrasounds and pressure parameters, same environment, etc. Similarly, the same pressure is applied to the silicon die in each configuration and result in a thickness of $90 \mu \mathrm{m}$ for the dieattach adhesive layer.

Tags have been chosen as representative of current smart tags technology in order to be tested in harsher conditions than usual. Accelerated life tests are expected to enlighten potential failure areas or defective parts for extreme conditions. Several material classes are thus considered as candidates for the ultimate configuration that will be used for continuity of care records in biorepositories.

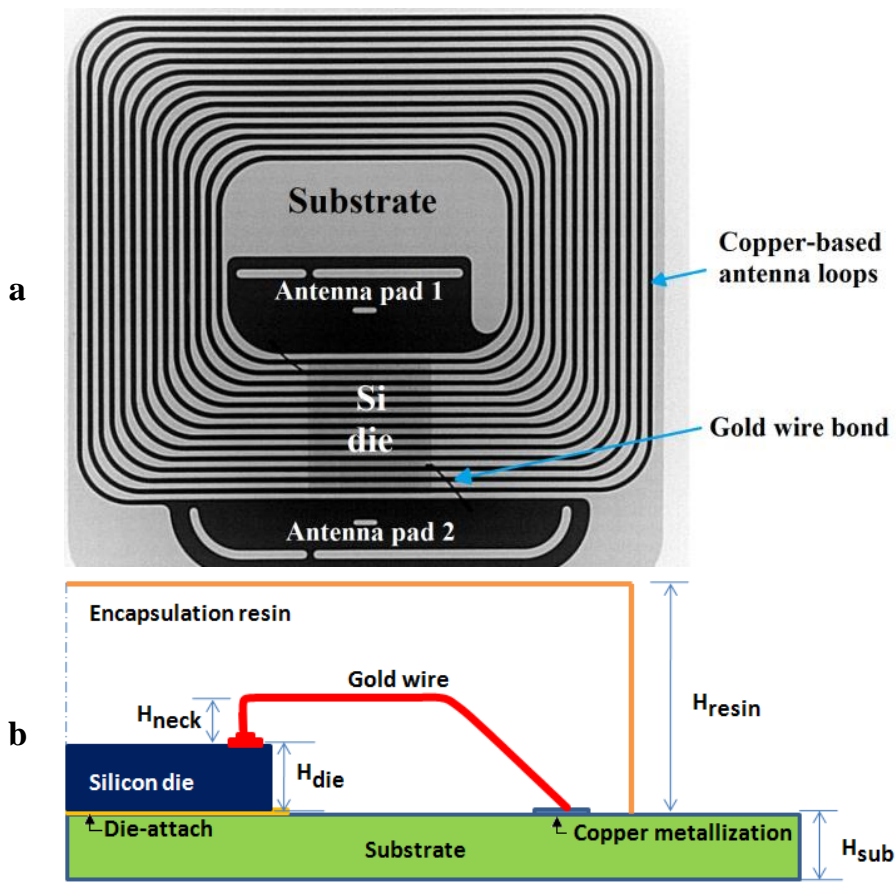

Figure 2: X-ray image of the configuration 3 tag (a) and simplified geometry used for modelling (b) 
Table 1: The different characteristics of tags. $\mathrm{H}_{\text {resin }}, \mathrm{H}_{\text {die }}$ and $\mathrm{H}_{\text {sub }}$ values are indicated in $\mu \mathrm{m}$.

\begin{tabular}{|l|c|c|c|c|c|} 
& Resin & Substrate & $\mathbf{H}_{\text {resin }}$ & $\mathbf{H}_{\text {die }}$ & $\mathbf{H}_{\text {sub }}$ \\
\hline Config. 1 & Thermal & Polyimide & 200 & 75 & 100 \\
\hline Config. 2 & UV & FR-4 & 500 & 150 & 150 \\
\hline Config. 3 & Thermal & FR-4 & 800 & 150 & 150 \\
\hline
\end{tabular}

Table 2: Material properties at $25{ }^{\circ} \mathrm{C}$ (if applicable, the variation of CTE is indicated within the working temperature range)

\begin{tabular}{|l|c|c|c|}
\hline Materials & \multicolumn{1}{c}{$\begin{array}{c}\text { Young's } \\
\text { modulus (GPa) }\end{array}$} & $\begin{array}{c}\text { Poisson's } \\
\text { ratio }\end{array}$ & \multicolumn{1}{c}{$\begin{array}{c}\text { CTE } \\
\left(\mathbf{1 0} / \mathbf{6} /{ }^{\circ} \mathbf{C}\right)\end{array}$} \\
\hline Copper & 130 & 0.34 & $16.4-18.5$ \\
\hline Gold & 78 & 0.42 & 14.4 \\
\hline Silicon & 130 & 0.28 & $2.49-3.61$ \\
\hline UV resin & 4 & 0.35 & 81 \\
\hline Th. resin & 0.27 & 0.3 & $47-195$ \\
\hline Die attach & 2.8 & 0.37 & $109-170$ \\
\hline Polyimide & 4.80 & 0.3 & 18 \\
\hline FR-4 & 2.21 & 0.3 & $13-26$ \\
\hline
\end{tabular}

\subsection{Experimental conditions}

Accelerated life tests are usually performed to determine and thus resolve design weaknesses in electronic components. The harsher the environmental conditions will be, the quicker the failures are expected to appear [13, 14]. ALT approach involves a batch of a few components undergoing stresses exceeding the level of in-service operations and enables identification of extrinsic (voids, cracks, and delaminations) as well as intrinsic (electronic disorder, lattice defects, and grain boundaries) failure mechanisms.

Prior to any test definition, mission profile has to be assessed to guarantee a sufficient accelerating factor for the determination of the mean time to failure (MTTF) of abovementioned configurations. Exhaustive thermal monitoring of RFID tags in the ultimate operational environment has been measured with a T-type thermocouple positioned in contact with the silicon die. Usually, in a biorepository, the tagged vials are removed from the liquid nitrogen and placed in gaseous nitrogen - about $10 \mathrm{~cm}$ above the liquid nitrogen level - to be handled for reading operations. Figure 3 indicates the difference of temperature slope and amplitude when the tag is placed from liquid to gaseous nitrogen - operational conditions for tag reading - and from liquid nitrogen to ambient atmosphere. This profile shows that temperature doesn't exceed $-150^{\circ} \mathrm{C}$ after 5 minutes in nitrogen vapours ensuring the biologic sample integrity. Since reading time is nearly instantaneous, a whole box of 81 cryotubes can thus be inventoried in less than 5 minutes.

For accelerated life tests, the tags were thermally cycled two hundred times between a cold tank of liquid nitrogen at - $196^{\circ} \mathrm{C}$ and a hot bath of fluorinated heat-transfer fluid at $120^{\circ} \mathrm{C}$. This last temperature was chosen as a compromise to prevent any thermal degradation of polymer parts within electronic packages, such as encapsulation resins or die attach adhesives. While accelerating the initiation of failures, thermal conditions above the glass transition of polymers would undoubtedly result in failure modes that are not likely to occur in operational conditions. To prevent those artefacts a moderated temperature of $120{ }^{\circ} \mathrm{C}$ was thus chosen. Considering the fact that biological samples temperature doesn't exceed $-150{ }^{\circ} \mathrm{C}$, the applied temperature difference is thus about seven times greater than what the smart tags is expected to undergo in operation which is thought to be a sufficient design margin. According to time-temperature data, a residence time in each bath has been set to 30 seconds. While only a few components are usually required in ALT tests, we opted for batches of 10 samples for each configuration to reinforce the significance of the experiment.

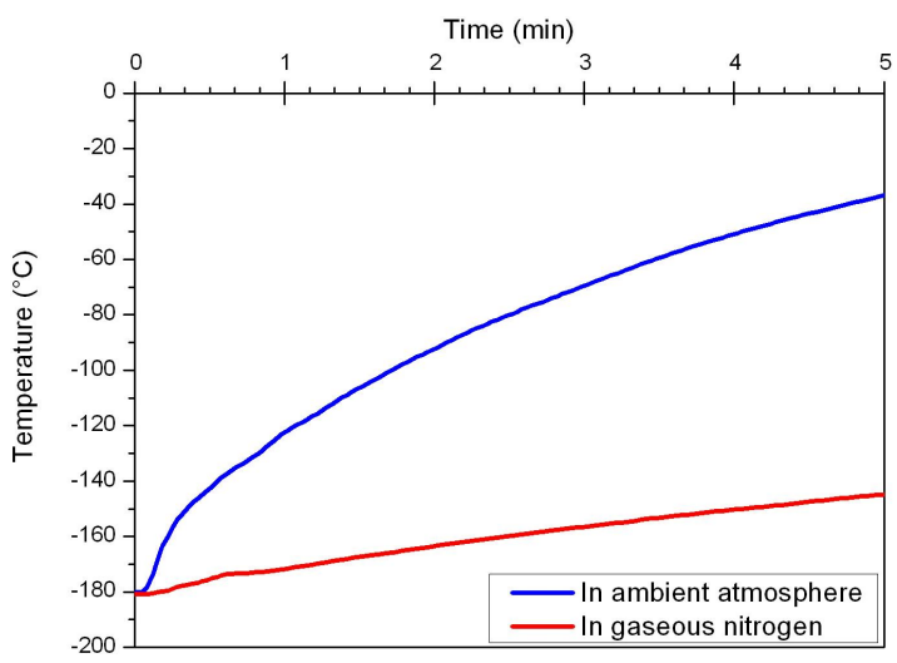

Figure 3: Thermal profile of the tag undergoing a temperature rise in operational conditions (red curve) for tags inventory compared with a temperature rise in ambient conditions (blue curve).

Experimental conditions are evaluated through finite element modelling with ANSYS software to assess the stress distribution and to exhibit failure modes to be considered during experiments.

\section{Finite element modelling}

\subsection{Modelling details}

For numerical simulations, two approaches have been followed due to geometry issues. Indeed, dimensions of the package and of the wire bonding differ so much that the meshing step has to be tailored to optimize computation time. Failure mechanisms are usually localized in the silicon die and in wires because of either material or geometry dependency. A 
finer mesh is therefore applied in the wire bond interconnect where interfaces, geometrical singularities and curvature areas usually exhibit higher stress field.

This issue is addressed by performing separate FEA models for each tag configuration (see Figure 4). A global approach is focused on material combination without considering wire bonding connections and is aimed to enlighten silicon die weaknesses due to the package design. The second approach uses a 3D-slice model for wire bonds to achieve a better resolution. Assembly symmetry planes are taken into account to reduce the number of elements to a half or a quarter. To avoid rigid body motion, the first node located at zero coordinate is a fixed point $\left(\mathrm{U}_{\mathrm{X}}=\mathrm{U}_{\mathrm{Y}}=\mathrm{U}_{\mathrm{Z}}=0\right)$. In addition, a linear elasticity condition is applied to all materials (see Table 2 ), except gold which is considered as a bi-linear elastoplastic material [15].

The smaller local model stands for a device slice along the wire bond axis and uses periodic boundary conditions to represent the effects of wire array. Further reduction of the model size is achieved by considering mirror plane symmetries in the wire; so that the slice width is eventually $100 \mu \mathrm{m}$ with a 26800 hexahedral elements mesh. The plane located at $100 \mu \mathrm{m}$ along the $y$-axis is attributed a $U_{Y}$-coupling condition since this plane is neither a free surface nor a symmetry plane. The general plane strain condition is adopted to ensure free movement of this plane along y-axis without any out-of-plane warpage. Other surfaces are assumed as free surfaces. The mesh in the interconnect is depicted in Figure 5.

In this finite element model, the reference has been set up at the room temperature, i.e. $25^{\circ} \mathrm{C}$, where stress and deformation are considered as zero in the package. While this approximation is correct for the configuration 2 where a UV encapsulation resin has been used and cured at room temperature, this in not suited any more for thermal resins which are processed at $60{ }^{\circ} \mathrm{C}$. Indeed, the process thus induces a residual stress within the package during the cooling down step. Nonetheless, this residual stress cannot be directly assessed experimentally during the reticulation process due to the absence of deformation of the package. Additionally, the residual stress initially within the silicon die is not known neither. The following results should thus be taken with care, and only considered as strain development relatively to the room temperature state. This being said, two constant thermal loads are applied to the package assembly. Its reference temperature is set at $20^{\circ} \mathrm{C}$. The first load corresponds to the assembly cooling in liquid nitrogen between $20^{\circ} \mathrm{C}$ and $-196^{\circ} \mathrm{C}$ $\left(\Delta \mathrm{T}=-216^{\circ} \mathrm{C}\right)$ within $1 \mathrm{~s}$, while the second corresponds to the assembly heating in the heat transfer fluid between $20^{\circ} \mathrm{C}$ and $120^{\circ} \mathrm{C}\left(\Delta \mathrm{T}=100^{\circ} \mathrm{C}\right)$ within $1 \mathrm{~s}$ also, with an intermediate standby step at room temperature during $13 \mathrm{~s}$ corresponding to the transfer time between both baths.

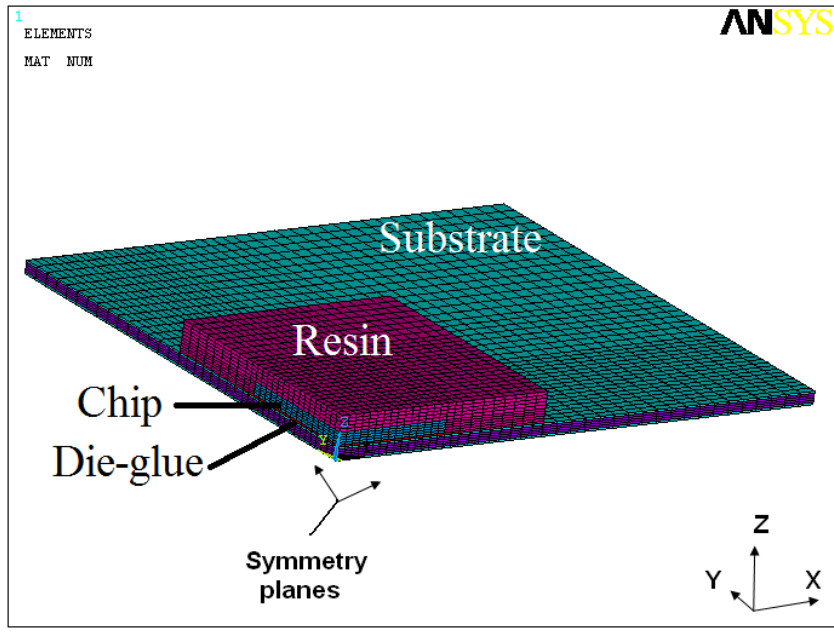

Figure 4: Package model of configuration 1

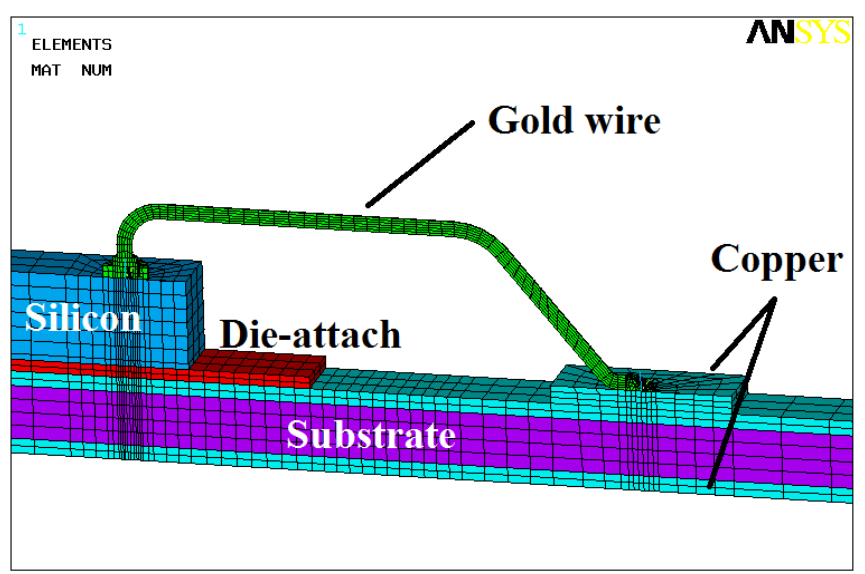

Figure 5: FE model of the wire bond interconnection.

\subsection{Simulation results}

As presented above, the package model enables investigation of stress distribution in the silicon die. Von-Mises stress maxima of each configuration under two thermal loads are listed in Table 3. Whatever the studied thermal load value, either $100^{\circ} \mathrm{C}$ or $-216^{\circ} \mathrm{C}$, the maximum Von-Mises stress in the silicon die is reached for configuration 2 . These values are nonetheless far below the silicon ultimate strength which is about $7 \mathrm{GPa}$. Configuration 2 uses UV resin whereas configurations 1 and 3 use thermal resin, which is much softer (the Young's modulus is smaller). So the first parameter which can affect stress distribution in the silicon die is the property of encapsulation resin. Another possible parameter is the encapsulation resin volume above the die. Indeed, the higher the resin is, the greater the resulting deformation will be. This hypothesis appears to be irrelevant when the maxima of stress distribution are compared. In fact, even though resin height is significantly different in configuration 1 and 3, the maximum stress values are close in both cases. 
Table 3: Maximum Von-Mises Stress in the silicon die under different thermal loads for all configurations

\begin{tabular}{|lcc|}
\hline Tag sample & $\boldsymbol{\sigma}_{\max }{ }^{\text {V-M }}(\mathbf{M P a})$ & \\
\cline { 2 - 3 } & $\Delta \mathrm{T}=-216^{\circ} \mathrm{C}$ & $\Delta \mathrm{T}=100^{\circ} \mathrm{C}$ \\
\hline Configuration 1 & 325 & 111 \\
\hline Configuration 2 & 547 & 249 \\
\hline Configuration 3 & 312 & 158 \\
\hline
\end{tabular}

Results concerning the 3D-slice model are investigated and summarized in Table 4. Configuration 3 exhibits the highest strain evolution during both thermal loads. The maximum stress value is estimated at $285 \mathrm{MPa}$ for a temperature of $120^{\circ} \mathrm{C}$ according to the finite element analysis. The Von-Mises strain distribution in this configuration under a $\Delta \mathrm{T}=100^{\circ} \mathrm{C}$ load is also shown in Figure 6. The highest strain value in the gold wire is localized at the neck of the ball bonding and at the interface with the die at the wedge side. It is in total agreement with our previous investigations and with literature which exhibit wire breaks close to these positions.

Table 4: Maximum Von-Mises Strain in wire bonding under different thermal loads for all configurations

\begin{tabular}{|lcc|}
\hline Tag sample & $\boldsymbol{\varepsilon}_{\max }^{\mathbf{V}-\mathbf{M}} \mathbf{( \% )}$ & \\
\cline { 2 - 3 } & $\Delta \mathrm{T}=-216^{\circ} \mathrm{C}$ & $\Delta \mathrm{T}=100^{\circ} \mathrm{C}$ \\
\hline Configuration 1 & 3.9 & 7.8 \\
\hline Configuration 2 & 4.9 & 2.4 \\
\hline Configuration 3 & 5.7 & 9.9 \\
\hline
\end{tabular}

Numerical results outline the key factors influencing the resistance of the wired interconnects to thermal cycling for emerging cryogenic applications. For instance, configuration 1 exhibits a lower strain rate in the gold wire than in configuration 3 , which indicates a decrease of thermal stress in the wire bonding when thermal resin height is reduced. Thus, a shrink of the resin height by a factor of 4 cuts the strain by 70 $80 \%$. On the other hand, using UV resin instead of thermal resin for encapsulation highly impact the strain rate. The strain is all the more significant as a positive thermal load is applied. Indeed, using $35 \%$ less of resin material than in configuration 3 , the strain rate drops off by $75 \%$ in configuration 2 where UV resin encapsulation is used. Strain amplitude between $-196^{\circ} \mathrm{C}$ and $+120^{\circ} \mathrm{C}$ provides high credit to the use of UV resin for cryogenic electronic applications since it is less affected by thermal expansion. The stress field in the wire bonding interconnect is thus affected as much by the resin cross-linking initiation method than by its height in the assembly.

\section{Experimental results and discussion}

During ALT tests, ten samples of each configuration have been cycled between liquid nitrogen and a heat transfer fluid heated at $120^{\circ} \mathrm{C}$. The first failure to be observed during the test appeared after 50 cycles is on configuration 3. Two additional failures were observed after 200 cycles. In the same time, one
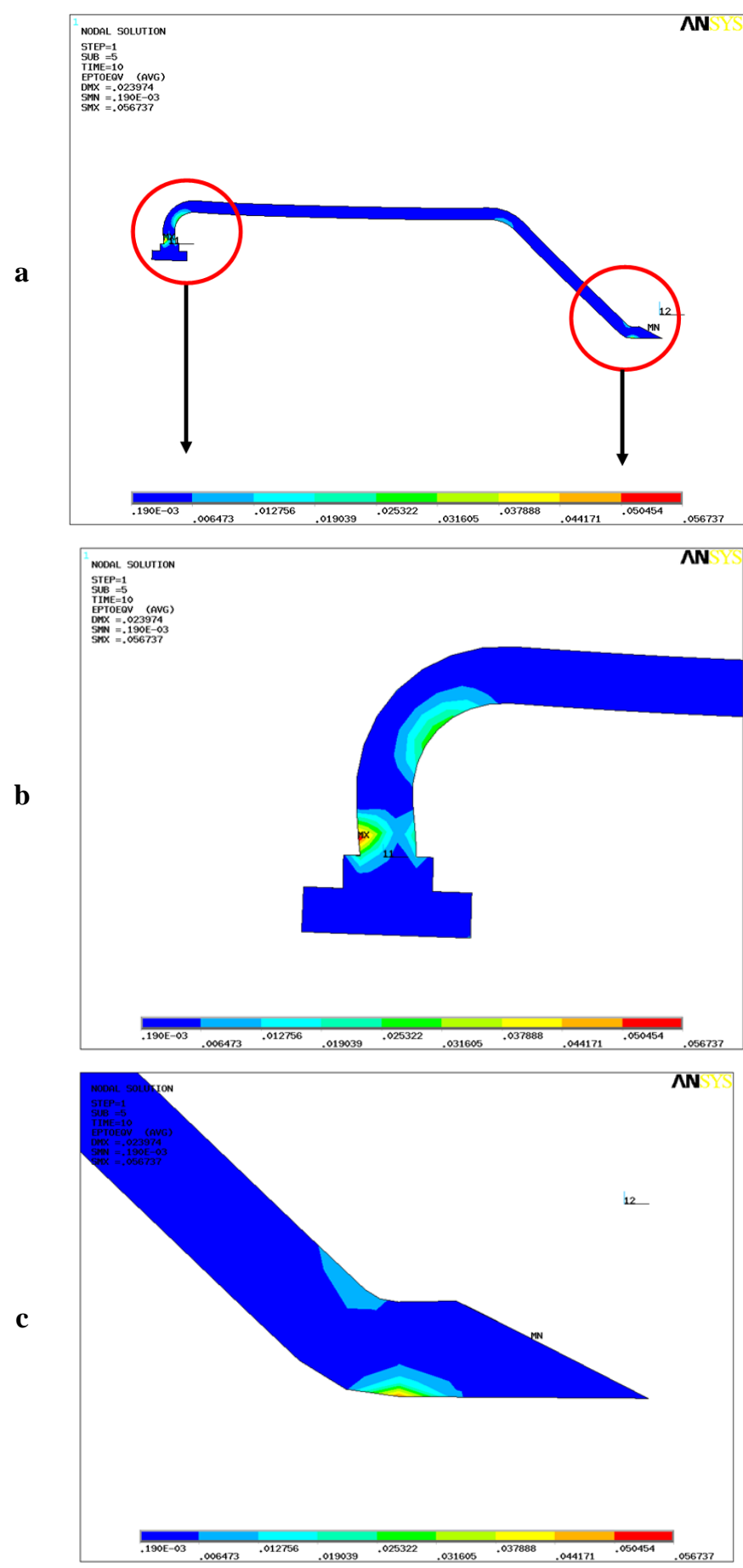

Figure 6: Global Von-Mises strain distribution in the wire bonding of the configuration $3\left(\Delta \mathrm{T}=100^{\circ} \mathrm{C}\right)$ (a) with details located at the ball-bond side (b) and at the wedge side (c).

failure is detected on configuration 1 while configuration 2 exhibits no defective behaviour at all after 200 cycles.

A failure analysis is then performed on the defective tags through non-destructive testing - such as scanning acoustic microscope (SAM) or X-ray radiography - before operating a chemical opening of the modules to make optical microscope and SEM observations. As regards to non-destructive analysis, 
previous FEM analysis proves to be an asset in locating likely root causes of failure. FEM indeed shed light on assembly weaknesses whose characterization can thus be optimized for non-destructive approach prior any aperture investigation. Acoustic microscopy and X-rays demonstrate good synergy for investigation of microelectronic package main failure modes. X-ray resolution enables detection of wire breaks and lifts, while the scanning acoustic microscope detects defects in silicon (such as die cracks) and delamination issues. Several failure modes have been highlighted by these analyses mainly on connection wires and on silicon die.

Acoustic microscopy analysis has been performed on configuration 1 and revealed the presence of a hypoechoic vertical line on the silicon die (see Figure 7). This characteristic signal originates from a difference in acoustic impedance between two layers. In this case, the darkness of the signal means that the signal transmission is more important than its reflection at the interface, i.e. the wave encounters a material with lower acoustic impedance at the interface. This gives credence to the presence of a crack across the die from side to side. Indeed, the acoustic impedance of silicon $\left(\mathrm{Z}_{\mathrm{Si}}=\right.$ $\left.20.04 \times 10^{6} \mathrm{~kg} \cdot \mathrm{m}^{-2} \cdot \mathrm{s}^{-1}\right)$ is larger than that of air $\left(Z_{\text {air }}=0\right)$, water $\left(Z_{\text {water }}=1.48 \times 10^{6} \mathrm{~kg} \cdot \mathrm{m}^{-2} \cdot \mathrm{s}^{-1}\right)$ or even an epoxy resin $\left(Z_{\text {epoxy }}=\right.$ $\left.3.12 \times 10^{6} \mathrm{~kg} \cdot \mathrm{m}^{-2} \cdot \mathrm{s}^{-1}\right)$. Optical microscopy observations were performed after a chemical attack with nitric acid to remove the encapsulation resin. A polarization difference is observed indicating a change in slope at the interface of the crack. Since this defect was not predicted by FEM analysis, the presence of an initial surface crack originating from the sawing operation can be assumed, located approximately at $380 \mu \mathrm{m}$ from the right edge of the chip. Crack propagation along a crystalline plane has then been initiated by the stress field inherent to thermal shocks and CTE mismatch between the die and the resin.

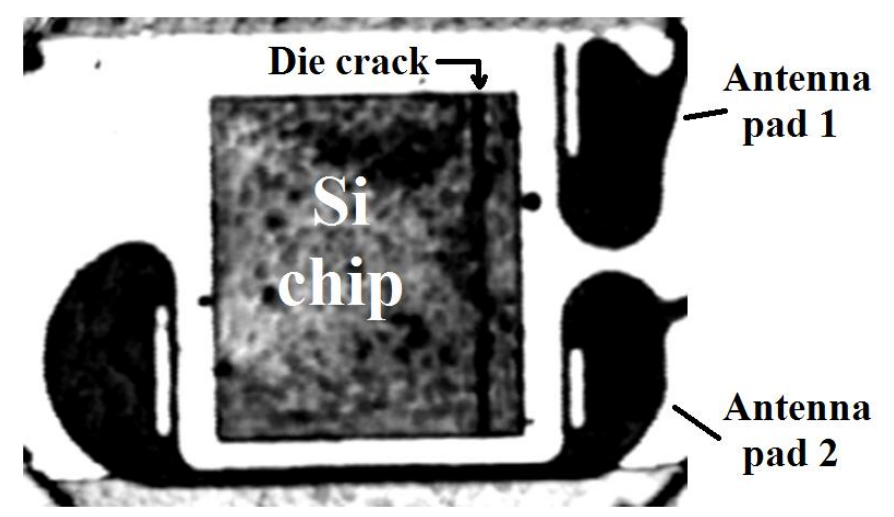

Figure 7: Scanning acoustic microscope image showing a hypoechoic signal attesting the presence of a die crack in configuration 1 .

Regarding configuration 3, the three failures involve wire connections between die pads and antenna pads. However, the position of these breaks varies from one module to another. X- ray radiography proved to be a particularly valuable asset for non-destructive analysis because of its high resolution and its ability to tilt the sample. Indeed, in most cases, a vertical observation of the sample does not discriminate the wire break and FEM analysis is a supportive tool to draw the attention to such defect mode. The first tag has failed before the fiftieth cycle and another one before the two-hundredth cycles. In both cases, X-ray imaging has highlighted a fracture at the neck of the ball bonding; commonly known as "neck break" (see Figure 8). Indeed, this transition zone is particularly vulnerable because of the high concentration of thermo-mechanical stress - as shown in previous part - due to the thermosonic wiring process [16]. Creep is caused by the expansion and compression of the encapsulation resin. Other potential root causes of these failures such as corrosion, causing a diameter narrowing, or a bad setting of the wirebonder inducing strain has been previously reported $[17,18]$.

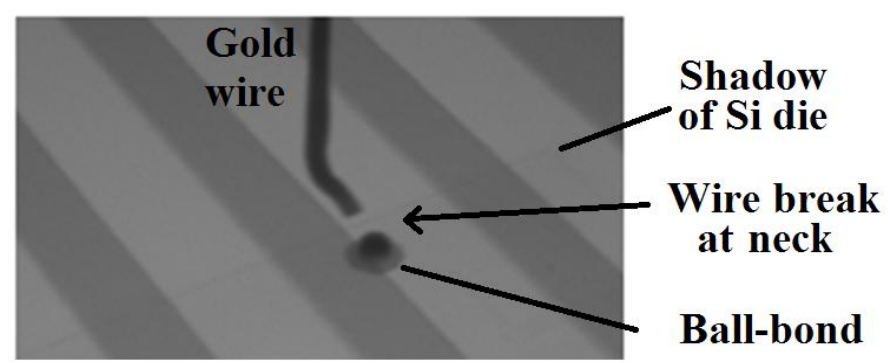

Figure 8: X-ray image of a broken gold bond wire after 50 cycles.

The last defective label of configuration 3 is also characterized by X-rays radiography and exhibits an unusually high number of failures with three breaks localized on wires: one at the neck of the wedge and the other two in mid-thread. Note that the wire being connected to the inner antenna pad concentrates two breaks against a single one for the outer pad, tending to confirm the presence of higher stress in the centre of the assembly (see Figure 9). The failure located at the wedge bond is the counterpart of that observed previously at the ball bond because it shares the same causes.

Considering the limited number of degrees of freedom in the resin, the wire is undergoing a creeping phenomenon, which explains not only the displacement of the wire, but also the twist and bending at the ball bonding (see Figure 9-b). This phenomenon of creep is caused by the contraction and expansion of the resin during cycling but is also favoured by the high temperature of the hot bath which increases the ductility of the wire and thus its deformation. This extension induces an area of localized necking which leads to a break if the stress is increased. FEM analysis showed that the gold wire reached the elastoplastic regime during thermal incursion of the ALT test, thus explaining the deformation. A SEM observation exhibits the necking area of the wire under tensile load (see Figure 10). With an initial section area of $845 \mu \mathrm{m}^{2}$ and a final 


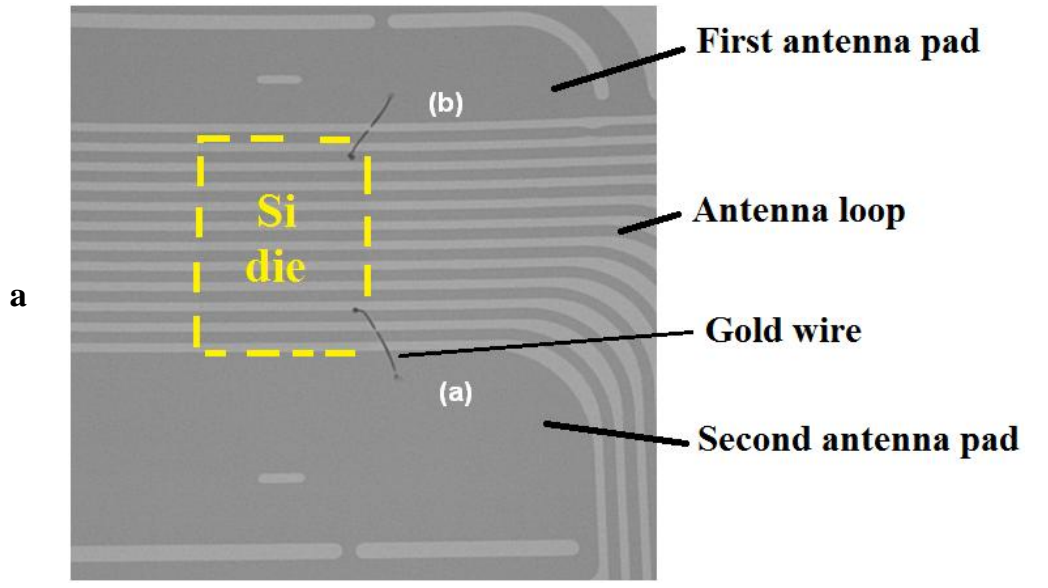

b
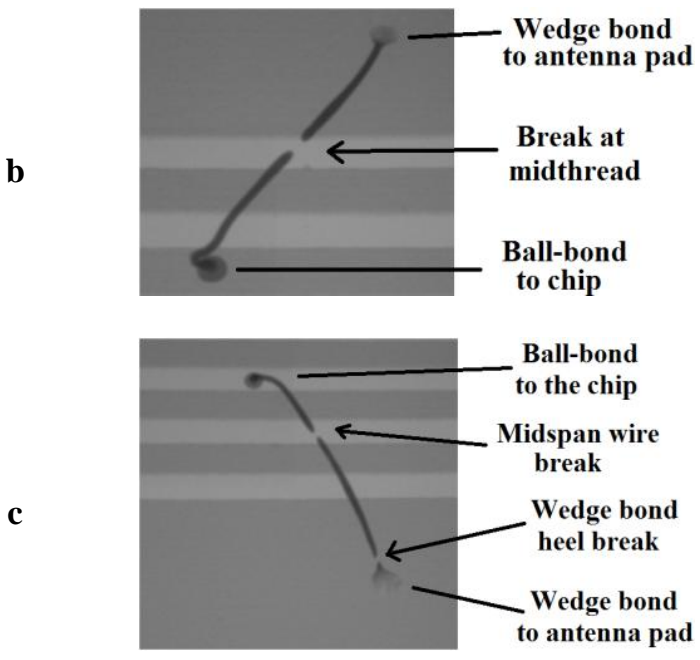

Figure 9: X-ray images of a configuration 3 sample where three wire breaks were detected with a 40 $\mu \mathrm{m}$ gap: global view (a), magnified view of the outer connection (b) and the inner connection (c) to antenna.

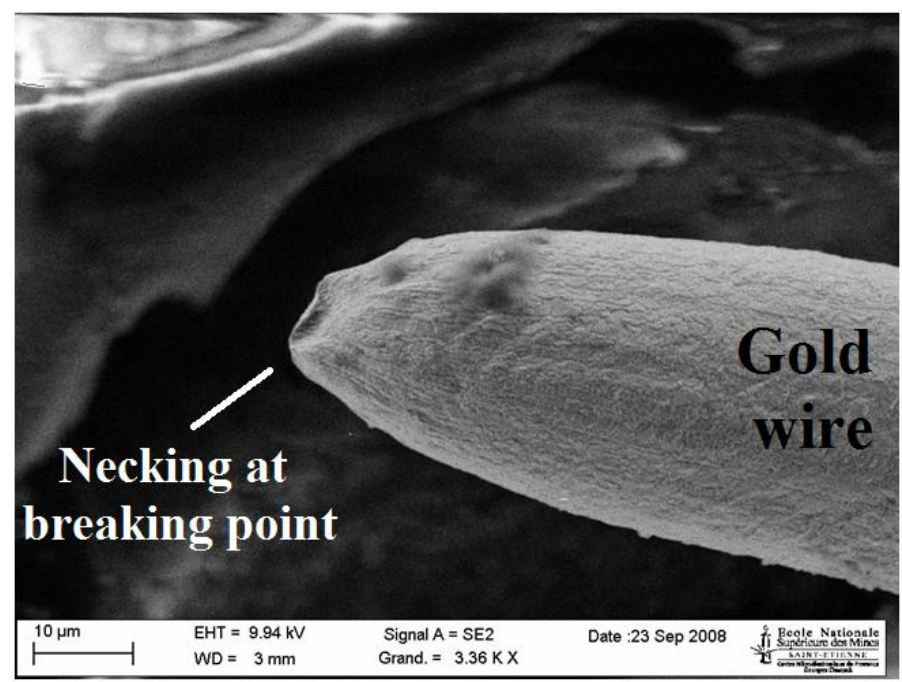

Figure 10: SEM image of the gold wire at the point break exhibiting a characteristic necking.

section of $51 \mu^{2}$, we can derive a necking of $94 \%$ when fracture happens, which shows a high ductility of the material, consistent with the literature [19]. More, the maximum force applied before the break has been derived to a value of 186 $\mathrm{mN}$. This force therefore reflects the outcome of the tension exerted by the resin on the wire during thermal stress due to CTE mismatch.

The main failure mode is thus identified as the wire break as a consequence of a succession of compressive and tensile stress exerted by the resin. Given that wire breaks only occurred when thermal resin was used in the assembly, its use in cryogenic application can be seriously challenged and UV resin preferred instead.

\section{Conclusions}

The development of a specific versatile bench for designing thermal reliability experiments in RF environment - the $\mathrm{T}$ REX - enabled the characterization of RFID tags for cryogenic applications. These tags aim to be used in biorepositories and undergo several transfers between a liquid nitrogen tank and room temperature. Thermal cycling through ALT was performed by T-REX between liquid nitrogen and a fluorinated heat transfer fluid heated at $120^{\circ} \mathrm{C}$. Experiments enlighten two main failure modes that have developed in less than 200 cycles. The main failure mode is assigned to wire breaks because of CTE mismatch between the encapsulation resin and the gold wires that entails wire necking. Another failure mode was a fracture observed in the silicon die which was not identified during finite element modelling. FEM analysis was performed on exact geometries of tags already available on market. FEM results showed good agreement with observed failures. In particular, simulations pointed out the configuration 3 as the weakest one which was confirmed by the highest number of wire failures. Encapsulation resin type and height have been highlighted as key parameters in the package design to achieve a sufficient reliability under the applied thermal load. Numerical and experimental analyses thus both recommended for the use of UV resin and for a lower amount of resin above the die to limit creep in gold wires. This advice will be integrated in the final product design jointly with technological and geometrical constraints to improve the thermal reliability in cycling and the data retention in harsh environment. 


\section{Acknowledgements}

This work was supported by DGCIS and local authorities funding within the framework of the PAC-ID santé project operated by the MISTRALS consortium.

The authors would like to acknowledge the precious help of Mr. J. Legeleux during the bench conception step.

\section{References}

[1] Bettendorf E, Malenfant C, Chabannon C. RFID technology and electronic tags to identify cryopreserved materials. Cell Preservation Technology. 2005;3(2):112-115.

[2] Housseman S, Absi N, Feillet D, Dauzère-Pérès S. Impacts of radio-identification on cryo-conservation centers through simulation. In: Winter Simulation Conference; 2009. p. 2065-2077.

[3] Ihmig FR, Shirley SG, Durst CHP, Zimmermann H. Cryogenic electronic memory infrastructure for physically related "continuity of care records" of frozen cells. Cryogenics. 2006 Apr;46(4):312-320.

[4] Hsu HC, Yu SW, Hsu YT, Chang WY, Lin MJ, Lin RM, et al. Parametric Study and Optimal Design in Wire Bonding Process for Mini Stack-Die Package. In: Electronic Packaging Technology, 2006. ICEPT '06. 7th International Conference on; 2006. p. 1-6.

[5] Su M, Boddaert X, Inal K. Numerical Investigations of Smart Card Module: Parametric Analysis and Design Optimization. Device and Materials Reliability, IEEE Transactions on. 2008;8(3):464-470.

[6] Ren W, Wang J. Shell-based simplified electronic package model development and its application for reliability analysis. In: Electronics Packaging Technology, 2003 5th Conference (EPTC 2003); 2003. p. 217-222.

[7] Mao CY, Chen RS. Packaging parameter analysis and optimization design on solder joint reliability for twin die stacked packages by variance in strain energy density (SED) of each solder joint. Microelectronics Reliability. 2008 Jan;48(1):119-131.

[8] Zhu WH, Stoeckl S, Pape H, Gan SL. Comparative study on solder joint reliability using different FE-models. In: Electronics Packaging Technology, 2003 5th Conference (EPTC 2003); 2003. p. 687-694.
[9] Loh WS, Corfield M, Lu H, Hogg S, Tilford T, Johnson CM. Wire Bond Reliability for Power Electronic Modules - Effect of Bonding Temperature. In: Thermal, Mechanical and Multi-Physics Simulation Experiments in Microelectronics and Micro-Systems, 2007. EuroSime 2007. International Conference on; 2007. p. 1-6.

[10] Bechel VT, Camping JD, Kim RY. Cryogenic/elevated temperature cycling induced leakage paths in PMCs. Composites Part B: Engineering. 2005 Mar;36(2):171-182.

[11] Bechel VT, Fredin MB, Donaldson SL, Kim RY, Camping JD. Effect of stacking sequence on micro-cracking in a cryogenically cycled carbon/bismaleimide composite. Composites Part A: Applied Science and Manufacturing. 2003 Jul;34(7):663-672.

[12] ISO-IEC. 14443 Identification cards - Contactless integrated circuit(s) cards - Proximity cards; 2008.

[13] Shapiro AA, Tudryn C., Schatzel D., Tseng S. Electronic packaging materials for extreme, low temperature, fatigue environments. IEEE Transactions on Advanced Packaging; 2010 May;23(2):408-420.

[14] Patterson RL, Hammoud A, Elbuluk M. Assessment of electronics for cryogenic space exploration missions. Cryogenics. 2006 Feb;46(2-3):231-236.

[15] Liu DS, Chao YC, Wang CH. Study of wire bonding looping formation in the electronic packaging process using the three-dimensional finite element method. Finite Elements in Analysis and Design. 2004 Jan;40(3):263-286.

[16] Schafft HA. Failure analysis of wire bonds. In: Annual Symposium of Reliability physics; 1973. p. 98-104.

[17] van Driel WD, Janssen JHJ, van Silfhout RBR, van GiIs MAJ, Zhang GQ, Ernst LJ. On Wire Failures in Microelectronic Packages. In: International Conference on Thermal and Mechanical Simulation and Experiments in Microelectronics and Microsystems (EuroSimE); 2004. p. 5357.

[18] Wang C, Sun R. The Quality Test of Wire Bonding. Modern Applied Science. 2009;3(12):50-56.

[19] Kim KS, Song JY, Chung EK, Park JK, Hong SH. Relationship between mechanical properties and microstructure of ultra-fine gold bonding wires. Mechanics of Materials. 2006 Jan;38(1-2):119-127. 